\title{
Lettre à José Garanger
}

Daniel Frimigacci

\section{(2) OpenEdition}

Journals

Édition électronique

URL : http://journals.openedition.org/jso/5731

DOI : 10.4000/jso.5731

ISSN : $1760-7256$

Éditeur

Société des océanistes

Édition imprimée

Date de publication : 30 juin 2009

Pagination : 11-12

ISBN : 978-2-85430-024-6

ISSN : 0300-953x

\section{Référence électronique}

Daniel Frimigacci, « Lettre à José Garanger », Journal de la Société des Océanistes [En ligne] 128 | janvier-juin 2009, mis en ligne le 30 juin 2009, consulté le 06 mai 2019. URL : http:// journals.openedition.org/jso/5731; DOI : 10.4000/jso.5731 


\title{
Lettre à José Garanger
}

\author{
par
}

\section{Daniel FRIMIGACCI*}

\section{Mon cher José,}

J'ai le cœur serré parce que je sais que pour la première fois tu ne répondras pas à ma lettre. Cependant, j'aimerais te dire ce que je n'ai pas eu la possibilité d'exprimer au cours de ces nombreuses années où je t'ai côtoyé. Je me souviens du jour où j'étais à la bibliothèque du Musée de l'Homme en compagnie de Jean-Pierre Roset ; c'est là que je t'ai aperçu pour la première fois. Une silhouette un peu massive, pas très grande, enveloppée dans une gabardine beige est sortie de la bibliothèque pour prendre le couloir qui menait à l'ascenseur. "Regarde, me dit Jean-Pierre, c'est José Garanger!» José ! Tu portais déjà ce gros cartable indissociable de ta personne. J'étais en année de licence et tu représentais beaucoup pour moi. Tu avais déjà cet air sérieux qui ne t'a jamais quitté, comme si tu portais les pires soucis du monde de la recherche! C'était peut-être le cartable qui était trop lourd !

José, c'est le Patron ${ }^{1}$ qui a formalisé la vision dite "école française d'archéologie » et qui a rajeuni la discipline de l'ethnoarchéologie où l'étude du vestige pour le vestige n'a aucun intérêt s'il ne débouche pas sur l'histoire de l'Homme. C'est le Patron qui a osé dire que l'on pouvait faire une anthropologie sociale des Australopithèques et c'est toi, José, le préféré de ses disciples, qui a mis en pratique la méthode au Vanuatu, appelé de ton temps "Condominium des Nouvelles-Hébrides ». Ton livre Archéologie des Nouvelles-Hébrides est un modèle du genre. Je connais plein d'envieux qui critiquent ce livre, mais tous le lisent et s'en inspirent. Si on les pousse dans leurs derniers retranchements, ils admettent que c'est génial. Tous les archéologues de l'Océanie tentent de suivre ta méthode : inventaire des sites et des traditions orales, fouilles archéologiques ciblées traditionnelles pour répondre aux questions de chronologie et de périodisation, mais aussi fouilles destinées à confirmer ou infirmer les sources de la tradition orale. Il est vrai que les problématiques de recherche en Océanie se prêtent à ce genre d'exercice et que les travaux remarquables de Jean Guiart t'ont fait gagner un temps précieux.

Mais j'aimerais aussi te dire, José, des choses plus intimes. Je n'oublierai jamais les repas pris ensemble à Noisy-le-Grand. À table, tu étais assis en face de moi, à droite se tenait Suzy et, avec l'aide d'une bonne bouteille de Bordeaux, nous devisions sur la recherche en général, les collègues, tu évoquais ta contrariété de constater que certains collègues anglo-saxons avaient une propension à te critiquer, injustement je dois dire. Et puis, nous parlions des choses de la vie, nous évoquions nos amis, notamment le regretté Jean-Pierre Maître qui était venu frapper à ta porte pour te demander de l'aide après, disons, son « désaccord » avec son directeur de Laboratoire de l'époque. Ce chercheur spécialiste du Tchad ne pouvait plus travailler sereinement. Alors, tu as montré tes qualités humaines, tu as accepté de le prendre dans ton équipe. JeanPierre fera un bref séjour en Océanie.

Nous parlions aussi de mes travaux. Tu n'étais pas très bavard, mais tu allais à l'essentiel et, à chaque fois, je m'en retournais avec un conseil judicieux. Tu as toujours été très proche de tes étudiants ; mais attention, sous tes airs bonhommes et simples, un tempérament de " mandarin » se cachait et il ne fallait pas quand même que tes étudiants aillent trop loin : il y avait des limites à ne pas dépasser !

*dfrimigacci@mail.wf 
Tu vois, José, je me souviens de tout cela, je me souviens de la chaleur de ces repas à Noisy, ceux aussi partagés avec Jack Golson où je vous écoutais évoquer vos jeunes années sur le terrain!
Merci José de tout cela, je te garderai dans mon cœur.

Daniel 